\title{
Correction to: Effect of direct "seeding" binders and embryonic sporophyte sizes on the development of the sugar kelp, Saccharina latissima
}

\author{
Schery Umanzor ${ }^{1,2}$ (D) Yaoguang $\mathrm{Li}^{1}$ (D) Charles Yarish $^{1}$ (D) \\ Published online: 4 December 2020 \\ (C) Springer Nature B.V. 2020
}

\section{Correction to: J Appl Phycol} https://doi.org/10.1007/s10811-020-02277-z

The original version of this article unfortunately contained a mistake. Some of the data of the first paragraph of section "The binder formulation experiments" were incorrect. The corrected is given below.

Calcium alginate (CA) formulations were prepared by blending $10 \mathrm{~g}$ of sodium alginate (CAS: 9005-38-3, Acros Organics, Belgium) with $1 \mathrm{~L}$ of either synthetic seawater (i.e., 29 and $35 \mathrm{ppt}$ ) or distilled water for $60 \mathrm{~s}$. Also, $4 \mathrm{~L}$ of $10 \%$ calcium chloride $\left(\mathrm{CaCl}_{2}\right.$; $\mathrm{MCB}$, USA) solution was prepared in seawater (i.e., 29 and $35 \mathrm{ppt}$ ) or distilled water to induce the transformation of sodium alginate into calcium alginate (Percival and McDowell 1967). The AtSea binder was made by blending $1.25 \mathrm{~g}$ of the product in $1 \mathrm{~L}$ of seawater (29 ppt as salinity on-site).

Publisher's note Springer Nature remains neutral with regard to jurisdictional claims in published maps and institutional affiliations.

The online version of the original article can be found at https://doi.org/ 10.1007/s10811-020-02277-Z

Schery Umanzor

sumanzor@alaska.edu

1 Department of Ecology \& Evolutionary Biology, University of Connecticut, Stamford, CT 06901-2315, USA

2 College of Fisheries and Ocean Sciences, University of Alaska Fairbanks, Juneau, AK 99801, USA 